\title{
ELABORAÇÃO E USO DE ANIMAÇÕES COMO ESTRATÉGIA PARA O ENSINO DE MECANISMOS DAS REAÇÕES ORGÂNICAS
}

\author{
Idália Helena S. Estevam ${ }^{a, *,(\odot), ~ E m m a n u e l l e ~ F e r r e i r a ~ R . ~ S i l v a ~}{ }^{\mathrm{b}}$ e Ana Paula dos S. Sacramento \\ aDepartamento de Ciências Exatas e da Terra, Universidade do Estado da Bahia, 41450-000 Salvador - BA, Brasil \\ bDepartamento de Química Analítica, Instituto de Química, Universidade Federal da Bahia, 41000-000 Salvador - BA, Brasil
}

Recebido em 11/01/2020; aceito em 28/05/2020; publicado na web em 08/07/2020

\begin{abstract}
ELABORATION AND USE OF ANIMATION AS STRATEGY TO TEACHING ORGANIC REACTIONS MECHANISM. The Chemistry of organic compounds is present in many aspects of life on the planet. In addition to many substances in our body being organic compounds, the energy matrix is based on burning fossil fuels, the biodiesel industry is also linked to organic reactions as well as the pharmaceutical industry. However, Organic Reaction Mechanisms is considered one of the most difficult subjects of undergraduate courses in chemistry. In order to improve the teaching-learning process, it was planned to elaborate animations on mechanisms of organic reactions, using simple programs accessible to all operating systems. Better than two-dimensional representation, the three-dimensional animations represent more concretely a model, at a macroscopic level, of what occurs on a sub-atomic scale. This is a new initiative to motivate students to study the concepts related to the subject of Mechanisms in Organic Chemistry, through research, planning and elaboration of animations. As a result, videos of the main reactions worked out in chemistry undergraduate courses were made, making the study of Organic Reactions more enlightening and understandable and demonstrated the use of computational technologies in the teaching of Organic Chemistry. It is an innovative, accessible, motivating and applicable teaching strategy in chemical courses.
\end{abstract}

Keywords: animation; organic reaction; mechanism.

\section{INTRODUÇÃO}

A Química Orgânica é de grande importância para a vida e a sociedade. Muitos produtos e materiais, utilizados diariamente, são formados por compostos orgânicos. $\mathrm{O}$ arranjo estrutural no átomo de carbono permite que sejam formados milhões de compostos orgânicos com as mais diferentes funções e propriedades. Produtos alimentícios como leite, pão, açúcar são constituídos de compostos orgânicos, incluindo vestuários, computadores, medicamentos, dentre outros. A maioria dos processos biológicos envolvem reações orgânicas. Diversas substâncias no corpo humano e nos seres vivos em geral são compostos orgânicos, tais como açúcares, aminoácidos, vitaminas, proteínas, lipídeos e glicídeos. Até mesmo os aromas de animais, os chamados feromônios, contêm compostos orgânicos. O papel da Química Orgânica é estratégico para o setor farmacêutico e de suma importância, sobretudo na pesquisa e desenvolvimento de novos medicamentos. ${ }^{1}$

Como consequência da grande aplicabilidade, importância e proximidade com o cotidiano, faz-se necessário o estudo de mecanismos de reações orgânicas durante a formação dos estudantes nos cursos de Química. No entanto, o ensino e aprendizagem de Mecanismos das Reações Orgânicas costuma ser um assunto complexo para a maioria dos graduandos em Química e áreas afins, sendo, dessa forma, considerada uma matéria difícil. Esse fato está relacionado à necessidade de abstração e de visualização tridimensional das moléculas, a fim de estabelecer uma correlação correta e lógica entre funções orgânicas, reatividade e mecanismos das reações. ${ }^{2-5}$ Grove e Bretz ${ }^{6}$ realizaram uma ampla pesquisa na qual foram identificadas as principais dificuldades no ensino e aprendizagem de Química Orgânica.

Além de conceitos básicos, como estrutura atômica e teorias de ligações químicas, o estudo de mecanismos das reações orgânicas envolve uma sequência de etapas com migração de elétrons, quebra

*e-mail: idaliahelena@gmail.com e formação de ligações, passando algumas vezes pela formação de estados de transição ou de intermediários, que podem sofrer rearranjos, em que também se discute sobre a estabilidade de intermediários até a formação do produto final, considerando os fatores cinéticos e termodinâmicos das reações em estudo. Devido a toda essa complexidade, os estudantes escolhem decorar as sequências de etapas, sem estabelecer a correlação adequada com a reatividade dos compostos orgânicos e os conceitos teóricos que explicam o assunto. ${ }^{7}$

Todos esses conceitos que envolvem o estudo dos mecanismos de reações orgânicas, geralmente, confundem os estudantes, o que prejudica a compreensão plena dos processos. Dessa maneira, muitos estudantes costumam reproduzir as etapas envolvidas nos mecanismos de reações orgânicas, sem o domínio conceitual do assunto, sem compreender adequadamente os fatores que explicam a reatividade dos compostos orgânicos, sem estabelecer uma transição entre os conceitos teóricos e os processos cognitivos de aprendizagem, o que não favorece a uma aprendizagem significativa. ${ }^{8,9}$

Para Johnstone, ${ }^{5}$ a aprendizagem em Química passa por três níveis de compreensão: o nível macroscópico, que é tangível, manipulável e, por isso, de acepção mais facilitada; o nível submicroscópico ou subatômico que, apesar de comprovações teóricas, não pode ser visto e depende de certo grau de abstração e imaginação para ser apreendido, ou seja, captado e incorporado como novo conhecimento; o nível simbólico ou representacional, como o nome diz, busca representar por fórmulas, equações e símbolos os aspectos relacionados aos processos Químicos. A abstração é um aspecto essencial para visualizar em nível subatômico, no qual ocorrem as reações e as transformações. Segundo Johnstone, um Químico experiente utiliza facilmente os três níveis de compreensão, lançando mão de todos esses, a depender do grau de profundidade do assunto estudado. Para o estudante iniciante, o nível macroscópico é mais fácil de entender e fazer conexões com os conhecimentos prévios. ${ }^{10,11}$ Bradley ${ }^{12}$ enfatiza que os três níveis de apreensão da Química não são independentes, posto que configuram um triângulo no qual cada nível ocupa um vértice e estão interligados. 
Esse autor apresentou, dentre outros exemplos, como os três níveis conectam importantes períodos da História da Química, identificando como tangíveis os experimentos de Lavoisier, como simbólico a contribuição de Berzelius na proposição de diversos símbolos usados para representar fenômenos e elementos químicos, chegando ao nível subatômico com a proposição do modelo atômico de Dalton.

O método tradicional de ensino, caracterizado por aulas expositivas, nas quais os mecanismos de reações são escritos no quadro ou apresentados em slides, pouco envolvendo o aluno no processo de ensino e aprendizagem, pode tornar a aula cansativa e desinteressante. ${ }^{13}$ Segundo os estudos de Freire, ${ }^{14}$ o estudante, ao ser colocado como protagonista na sala de aula, por meio da valorização de experiências prévias, tem sua vivência aproveitada pelo educador em associação ao conteúdo estudado, o que facilita a aprendizagem. Dessa forma, ensinar não seria apenas transferência de conteúdos, mas sim uma proposta de construção de conhecimento para e pelo estudante a partir da identificação de suas potencialidades. Consequentemente, os métodos tradicionais foram muito criticados por esse educador, para o qual a ideia de ensinar está voltada à valorização do estudante e à postura crítica do professor.

Para pôr em prática uma nova metodologia que auxilie a compreensão dos alunos em torno das questões estruturais relacionadas aos mecanismos das reações orgânicas, o docente costuma usar diferentes materiais didáticos e buscar formas motivadoras que dinamizem a sua prática pedagógica, trazendo exemplos que contextualizem os fatos estudados. ${ }^{15,16}$

Objetivando ajudar o estudante a melhorar a sua capacidade imaginativa, sobretudo na percepção dos fenômenos relacionados às reações orgânicas, podem-se utilizar comparações e generalizações para uma aprendizagem efetiva a partir de modelos. Sevian e colaboradores $^{11}$ investigaram a habilidade dos estudantes adquirirem as noções abstratas e concluíram que a realização de problemas baseados em modelos facilita os processos de abstração.

A fim de contornar as dificuldades de aprendizagem, é recomendável a diversificação de estratégias metodológicas e dos tipos de atividades realizadas, como também a utilização de materiais didáticos que representem os processos em escala macroscópica. ${ }^{17,18}$ Para Moran, os recursos tecnológicos vêm surgindo para auxiliar o processo educacional. Considera-se que o professor tem um papel fundamental na inserção das novas tecnologias, mediando de forma criativa e participativa a sua utilização no espaço da sala de aula. ${ }^{19}$ Os recursos tecnológicos disponíveis hoje auxiliam significativamente o ensino e a aprendizagem dos conteúdos de ciência e de áreas afins, pois os modelos tridimensionais e as animações são boas ferramentas de modelagem para representar as estruturas dos compostos orgânicos e a reatividade desses, facilitando a compreensão e a aprendizagem de mecanismos de reações orgânicas.

No momento, mostra-se importante realizar a diferenciação entre os modelos teóricos da matéria, executados por complexos cálculos computacionais e baseados na Equação de Schrödinger, os quais foram desenvolvidos por químicos teóricos no intuito de descrever ou de prever as propriedades das moléculas, de outras representações e modelos tridimensionais físicos ou virtuais. Esses, por sua vez, são baseados nas teorias estruturais e criados para facilitar a visualização, a comunicação e a interpretação de alguns conceitos.

Freeman e colaboradores ${ }^{20}$ realizaram um estudo estatístico que comparou o desempenho dos alunos de ciência em uma aula convencional e a relação com outros alunos em uma aula baseada na aprendizagem ativa. $\mathrm{O}$ estudo concluiu que, apesar de o ensino tradicional continuar sendo muito utilizado no ensino superior, as evidências mostram que a aprendizagem ativa, prática da sala de aula invertida, pode levar a um aumento no desempenho do estudante. Nesse sentido, Backes e colaboradores ${ }^{15}$ aplicaram a metodologia ativa para o ensino de Química Orgânica através da estratégia denominada "world cafe". Nesse trabalho, as autoras utilizaram temas geradores para discutir conceitos ligados à Química Orgânica, em que os estudantes discutiram e aprofundaram os conhecimentos em torno dos temas, despertando a sua capacidade de argumentação e de conscientização. Assim, essa nova metodologia ajuda na formação de um cidadão crítico, argumentativo, dotado de conhecimento científico.

A abordagem construtivista reconhece a importância do conhecimento prévio, pois este auxilia e motiva a aprendizagem de novos saberes e a construção de outros, uma vez que estabelece uma relação direta com o objeto de estudo, instigando, assim, as capacidades cognitivas do educando, facilitando a construção do conhecimento a nível mental, como afirma Seery. ${ }^{21}$ Adicionalmente a esse processo de construção, está a elaboração de objetos de aprendizagem, que se constitui em uma boa estratégia para promover uma aprendizagem significativa, visto que o estudante se debruça diante das questões teóricas para apresentar um bom material didático, acabado e aplicável. $^{22,23}$

O presente trabalho visa avaliar uma nova estratégia didática que envolva o planejamento, a elaboração e o uso de animações de mecanismos de reações orgânicas durante o semestre letivo, com uma turma de Química Orgânica II, em que são estudados a reatividade dos compostos orgânicos e os principais mecanismos das reações orgânicas. Os estudantes estão no centro do processo de ensino e aprendizagem, segundo a perspectiva construtivista, na qual o conhecimento é construído a partir do envolvimento concreto do aluno com o objeto de estudo.

Essa atividade opera alto grau de abstração dos estudantes, a partir da manipulação de modelos tridimensionais, nos quais as formas e os volumes buscam representar as moléculas reais, além de ler e reler o conteúdo para explicar, resumidamente em uma legenda, as etapas dos mecanismos, evidenciando quando da formação de intermediário, bem como a passagem por um complexo ativado ou estado de transição. É uma proposta moderna em que os próprios educandos planejam, preparam as imagens, criam suas próprias animações e legendas, convertendo-as para o formato de vídeo, o qual, após finalizado, será socializado entre os colegas da turma e utilizado nas discussões sobre os mecanismos estudados.

\section{Uso das TICs desafios e potencialidades}

O desenvolvimento das Tecnologias de Informação e Comunicação (TICs) e o crescimento do acesso e uso de computadores pessoais, associados ao surgimento da internet, fizeram com que tais recursos passassem a ser cada vez mais utilizados em sala de aula. ${ }^{18}$ Como expressa Ponte, ${ }^{24}$ as TICs fazem parte do nosso cotidiano nas mais diversas atividades, a exemplo das transações bancárias, do uso do telefone, da compra de passagens e na comunicação em geral. Nas universidades, o uso desses instrumentos facilita a pesquisa bibliográfica, a elaboração de trabalhos acadêmicos, a comunicação entre grupos de pesquisas, o uso de programas computacionais em rede e também na elaboração de material didático. Atualmente, as editoras de livros, por exemplo, aderiram à virtualidade, disponibilizando a versão eletrônica para download, exercícios on-line, jogos, algumas animações, hipertextos, dentre outros. ${ }^{25,26}$ Por meio da interatividade, esses recursos visam à facilitação da aprendizagem, melhorando a visualização dos conteúdos e, por conseguinte, a sua melhor compreensão.

A parceria entre tecnologia e ensino tem início com a implantação de laboratórios de informática e com a inserção dos computadores no ambiente escolar, iniciativas resultantes de políticas públicas voltadas para a introdução de educação tecnológica nas escolas. Esse é um sinal da implementação dos recursos computacionais em muitas 
salas de aulas brasileiras que, há até pouco tempo, não se observava. Nos últimos anos, é inegável o avanço tecnológico nos mais diversos ramos da sociedade. ${ }^{27}$ No setor educacional, porém, esse fenômeno foi pouco observado. A educação permaneceu fechada a esse novo panorama social referente à adoção das novas tecnologias, enquanto os profissionais de ensino resistiram a qualquer tentativa de aplicá-las. Mesmo assim, não suportando as investidas tecnológicas, a escola, hoje, diz se "apossar" dessa nova proposta, apesar de fazê-la ainda com grande dificuldade. ${ }^{28}$

Sobre a importância das TICs para o ensino de Química nos últimos 30 anos, Leite ${ }^{29}$ fez uma revisão, mostrando como o uso dos computadores pode auxiliar, em parte, o ensino de Ciências e salientando o papel secundário que foi delegado ao computador em sala de aula, com o passar dos anos. Para esse autor, a linguagem audiovisual, principalmente os vídeos, tem a vantagem de utilizar imagens além de palavras, o que pode tornar o ensino mais atrativo e trazer maior impacto sobre o livro ou a aula expositiva. Na última década de sua pesquisa, Leite observou o crescimento de trabalhos com dispositivos móveis. Por outro lado, apesar da tendência crescente do uso das tecnologias no ensino, o autor reforça o imprescindível papel do professor no uso crítico e adequado destas tecnologias.

Conforme afirma Rezende: ${ }^{13}$

A introdução de novas tecnologias na educação não implica necessariamente novas práticas pedagógicas, pois podemos com ela apenas vestir o velho com roupa nova, como seria o caso dos livros eletrônicos, tutoriais multimídia e cursos a distância disponíveis na Internet, que não incorporam nada de novo no que se refere à concepção do processo de ensino aprendizagem.

Sendo assim, de modo geral, os recursos audiovisuais apoiam o processo de ensino e aprendizagem entre os estudantes de Química e, quando usados no momento e da forma adequada, podem auxiliar na aprendizagem de muitos conteúdos de alta complexidade. ${ }^{30}$ No caso de reações orgânicas, a animação tem a contribuição da movimentação para representar a dinâmica das moléculas e suas interações. Essa prática se diferencia do método tradicional, no momento em que o aluno torna-se protagonista no processo de ensino e aprendizagem e constrói um objeto que auxilia a aprendizagem do assunto estudado. O professor atua como mediador, valorizando o conhecimento prévio dos estudantes e provocando o uso criativo de aplicativos que a maioria dispõe em seus aparelhos (smartphones, notebooks, tablets, etc.). Desse modo, a animação torna-se realmente satisfatória, não como mero fim ilustrativo ou para chamar atenção, mas buscando auxiliar o estudante a retirar as informações necessárias, favorecer a construção de modelos mentais, para melhor apreender o conteúdo abordado.

\section{Tecnologias educacionais para o ensino de Química Orgânica}

Visando facilitar a aprendizagem sobre mecanismos de reações orgânicas, diversas tecnologias educacionais têm sido usadas. Muitos professores utilizam modelos físicos ou virtuais, oportunizando ao estudante, de alguma forma, a visão espacial em escala macroscópica, podendo assim explicar melhor aspectos como polaridade das ligações, impedimento estérico, estereoquímica, estereosseletividade, polarizabilidade, dentre outros. ${ }^{31}$ Usar um recurso de imagem para o ensino destes assuntos ratifica o pensamento de Sorden $^{32}$ e Mayer ${ }^{33}$ para os quais, a imagem e o texto devem ser apresentados simultaneamente. Dessa forma, segundo os autores, os educandos associam o que está sendo dito (as palavras) ao que está vendo (as imagens), e podem assimilar melhor o conteúdo trabalhado. ${ }^{32-34}$
Para Sorden, ${ }^{32}$ a instrução apoiada por multimeios visa facilitar a aprendizagem na tentativa de potencializar a capacidade de cognição, memorização, codificação e produção de novas relações. Consequentemente, o estudante pode aprender mais profundamente, através da associação entre o estímulo visual com o estímulo auditivo. ${ }^{33}$ Para o ensino de mecanismos de reações orgânicas, a exemplo de mecanismos de substituição nucleofílica alifática e eliminação, a animação auxilia o processo cognitivo de aprendizagem, através da representação de modelos tridimensionais em movimento, que contribui para a abstração dos complexos fenômenos envolvidos durante as reações.

Mayer $^{34}$ esclarece que os estudantes aprendem melhor devido ao efeito de "contiguidade", quando os recursos, que associam imagem e texto, são apresentados de forma sincronizada, através de locução ou legenda, juntamente com as imagens. Entretanto, faz-se necessário não sobrecarregar os dois canais sensoriais, o canal auditivo e o visual, em função das limitações cognitivas do indivíduo. Mayer e colaboradores têm demonstrado que cada canal no sistema de processamento neural possui capacidade limitada, e apenas uma quantidade restrita de processamento cognitivo ocorre no canal verbal e também no canal visual. Os pesquisadores apontam que a redução dessa carga cognitiva em recursos multimídias pode facilitar a aprendizagem e, dessa maneira, sugerem que as animações apresentem imagens claras e poucas informações visuais. Recomenda-se ainda o uso de vídeos com narração ou legendas curtas. ${ }^{35}$

Segundo Raiyn e Rayan, ${ }^{36}$ quando o aluno tem contato com estruturas $2 \mathrm{D}$ e $3 \mathrm{D}$, encontradas nos livros didáticos e modelos moleculares físicos, respectivamente, ele começa a desenvolver o pensamento abstrato auxiliado por modelos macroscópicos que favorecem a elaboração de constructos mentais, alcançando a abstração e visualização espacial, especialmente por meio da transposição a níveis subatômicos e de fenômenos, tais como: interações interpartículas e fórmulas estruturais, e relacionando-as com suas propriedades físicas e químicas.

A presente estratégia utiliza os níveis simbólico (representacional) e macroscópico (tangível) para representar as estruturas moleculares, visto que esses níveis são mais fáceis para que o educando alcance o grau de abstração suficiente a fim de perceber as representações que ocorrem no nível subatômico. ${ }^{37}$

Ferreira e Arroio ${ }^{38}$ lembram que o uso de recursos audiovisuais, programas educativos transmitidos por rádio e programas de televisão, sempre foram aplicados como alternativa para o ensino. Essas propostas didáticas visavam promover melhor interatividade durante as aulas, o que fortalecia o potencial cognitivo dos sujeitos, melhorando a qualidade de sua aprendizagem..$^{38}$ Almeida e colaboradores ${ }^{39}$ investigaram a aplicação de vídeos educativos para auxiliar o ensino usando a linguagem audiovisual (vídeos) para trabalhar a evolução das teorias atômicas. A pesquisa fundamentou-se na análise de programas educacionais veiculados na televisão brasileira desde a década de 1970. Um dos programas pioneiros foi o "Projeto Minerva", voltado para a educação de adultos, tratava-se de um programa de rádio, obrigatório, lançado naquela época pelo Ministério de Educação e Cultura. Em 1995, a Rede Globo de Televisão iniciou a transmissão de uma série de programas educativos cujo nome foi "Telecursos", passando a ser chamada de "Telecurso 2000”, após uma reformulação no conteúdo, conferindo-lhe melhor contextualização e problematização; essa série se constituiu em material de apoio para muitos estudantes do ensino médio nas diversas áreas do conhecimento.

Com o surgimento dos computadores pessoais, alguns livros passaram a incluir um CD-ROM contendo vídeos sobre mecanismos, algumas animações, diversas imagens e quadros explicativos. ${ }^{40}$ Todas essas possibilidades, quando usadas de forma adequada, ampla e 
criativa, podem potencializar os recursos que auxiliam o estudante a desenvolver as imagens mentais dos processos que ocorrem em nível molecular com vistas à facilitação da aprendizagem.

No ensino de mecanismos de reações orgânicas, encontram-se portais em diferentes Universidades dos Estados Unidos e países da Europa, com animações de mecanismos de reações, tais como: 1) Mechanisms in Motion - Organic Chemistry Animation: ${ }^{41} \mathrm{em}$ formato de CD, no qual são apresentadas animações dos mecanismos de reações orgânicas com imagens tridimencionais, produzido e vendido pela Universidade da Califórnia. 2) Mechanism Inspector: ${ }^{42}$ não mostra animações, em vez disso possui cartões explicativos com hipertextos, slides e testes interativos, produzido pela Royal Society Chemistry. 3) Organic Chemistry - Animated by Roger Frost: ${ }^{43}$ possui muitos vídeos de laboratórios virtuais, poucas animações, mas o acesso é cobrado. 4) ChemTube $3 D:^{44}$ portal da Royal Society Chemistry, disponibiliza diversas reações com mecanismos e animações, as quais não apresentam narração ou legenda, apenas as imagens.

No Brasil, Baptista ${ }^{45}$ elaborou uma tese na qual utilizou cálculos teóricos para a construção de diversas estruturas e animações em 3D usando o programa Blender ${ }^{\circledR}$. Esse trabalho está disponível on-line no site: http://www.quimica3d.com/indexBR.php. Neste site, é possível ter acesso à Tese e visualizar as animações. Contudo, o trabalho de Baptista não apresenta mecanismos de reações orgânicas; as animações relativas à Química Orgânica demonstram a inversão da amônia e a reação de inserção do monóxido de carbono, ambos com ênfase na teoria do orbital molecular.

Recursos Virtuais voltados ao ensino têm sido compilados, armazenados e disponibilizados em bancos de dados nacionais e internacionais. O ChemTube3D é o único portal digital de acesso livre, em que podem ser encontradas animações de mecanismos de reações orgânicas. No Brasil, o Banco Internacional de Objetos Educacionais (BIOE) disponibiliza alguns gifs animados e animações, mas os poucos que estão relacionados com Química Orgânica não mostram mecanismos de reações. ${ }^{22-46}$ O Laboratório Didático Virtual (LABVIRT) apresenta muitas animações nas áreas de ciências, a exemplo das que tratam da nomenclatura de alcoóis e da identificação de gasolina adulterada; no entanto, também não traz no seu conteúdo reações orgânicas e seus mecanismos. ${ }^{47-49}$

Apesar da importância pedagógica no uso de imagens, a literatura atual não possui exemplos em que as animações são elaboradas com o propósito de ensinar Mecanismos de Reações Orgânicas, sobretudo em português, ou até mesmo em objetos educacionais com animações sobre reações orgânicas. Mesmo quando se percebe a existência de animações, essas foram elaboradas por programadores e estão descritas em outro idioma, o que desestimula, afasta e dificulta a utilização desses vídeos, prejudicando o acesso dos estudantes.

No ensino de Química Orgânica em especial, não raro, observa-se nos livros didáticos o uso de figuras ou modelos, já na graduação, os materiais recorrem à imagem de modelos moleculares para devida ilustração, ou ainda, em alguns casos, o próprio livro traz links que, ao acessá-los, os seus leitores podem encontrar mais imagens ou vídeos em 2D ou em 3D, facilitando o entendimento sobre determinada estrutura e, por conseguinte, melhor assimilação do conteúdo, o que pode auxiliar a aprendizagem. O website do livro "Química Orgânica”, de Paula Bruice, possui recursos visuais, traz algumas animações que não apresentam legenda, não estão disponíveis em todos os capítulos e são narradas em inglês. ${ }^{26}$ Conforme afirma Jonhstone, a visão de modelos em escala macro é de suma importância, pois favorece a correta compreensão estrutural para alcançar o nível de abstração necessário ao domínio dos conceitos em torno do assunto estudado. Imagens e animações são fundamentais, pois representam em escala macroscópica fenômenos que ocorrem em escala subatômica, o que demanda do pensamento abstrato, difícil de ser aplicado por parte dos estudantes nos níveis inicias. ${ }^{50,51}$

As animações podem ser definidas como a apresentação de uma sequência de imagens, criadas artificialmente e, posteriormente, ordenadas quadro a quadro, o que lhes concede uma aparência de movimentação. Constam na literatura, animações no ensino de Química Orgânica para a síntese de heterocíclicos. ${ }^{52}$ Apesar das vantagens obtidas com o apoio de animações no ensino de Química, esse autor enfatiza que os recursos computacionais não são utilizados na sua totalidade. Dessa forma, o trabalho de Babaev ${ }^{52}$ explora outras potencialidades do computador, mostrando aos alunos um novo software criado para fazer animações, demonstrando, assim, o uso criativo das novas tecnologias. Visto que as reações não acontecem de modo estático, como são representadas nos livros, exibir uma representação mais dinâmica em que as reações possam mostrar a movimentação das moléculas é essencial para o ensino de Mecanismos das Reações Orgânicas. ${ }^{16,33,53}$

Essa prática se diferencia da prática tradicional, no momento em que o aluno torna-se protagonista do processo de ensino e aprendizagem e constrói as animações, trata-se de um objeto educacional que auxilia a explicação e a compreensão do assunto estudado. As imagens tridimensionais se aproximam das estruturas realistas, o que aguça a imaginação e auxilia o estudante a visualizar os fenômenos subatômicos, desenvolvendo o pensamento abstrato. O professor atua como mediador, valorizando o conhecimento prévio dos estudantes sobre estruturas e interações interpartículas, provocando o uso criativo de aplicativos de que a maioria dos estudantes dispõem em seus computadores, mas não tinham sido usados para desenvolver animações.

Acreditando-se na necessidade de uma abordagem mais ampla e dinâmica para o ensino de Química Orgânica, desenvolveu-se neste trabalho a elaboração e o uso de algumas animações de Mecanismos das Reações Orgânicas, resultante de uma atividade incluída no processo avaliativo continuado do componente curricular Química Orgânica II, do curso de Licenciatura em Química, cujo conteúdo é o estudo das principais Reações Orgânicas.

Este trabalho de pesquisa apresenta uma proposta moderna, em que os próprios estudantes planejam, preparam as imagens, criam suas próprias animações, as respectivas legendas, convertendo-as para o formato de vídeo, usando programas simples e de fácil acesso.

\section{MATERIAIS E MÉTODOS}

A atividade foi realizada junto aos estudantes do componente curricular Química Orgânica II, oferecido no $4^{\circ}$ semestre do curso de Licenciatura em Química, período em que são estudados os principais mecanismos das reações orgânicas, tais como: mecanismos das reações de Adição à dupla $\mathrm{C}=\mathrm{C}$; Eliminação $\mathrm{E} 1$ e E2; Substituição Nucleofílica Alifática $\mathrm{S}_{\mathrm{N}} 1$ e $\mathrm{S}_{\mathrm{N}} 2$; Substituição Eletrofílica e Nucleofílica no Anel Aromático; Adição à Carbonila; Reações de Condensação e de Substituição à Carbonila; além dessas, ainda são estudadas as reações radicalares e reações de oxidação e redução. A cada semestre, são matriculados de 10 a 15 estudantes. A elaboração das animações foi executada em duplas e fez parte do processo avaliativo continuado do componente Química Orgânica II.

$\mathrm{O}$ presente trabalho, desenvolvido junto à turma do primeiro semestre de 2015, foi selecionado como exemplo para avaliar aquela estratégia que vinha sendo testada e utilizada em algumas turmas e aplicada em todos os semestres desde então. Foram escolhidos os mecanismos de substituição nucleofílica alifática $S_{N} 1$ e $S_{N} 2$ e os mecanismos de eliminação E1 e E2, assuntos da segunda unidade, para a elaboração das animações.

As animações foram planejadas e elaboradas pelos próprios estudantes, sob orientação docente. A construção 2D, quadro a 
quadro, foi o método escolhido por ser simples e utilizar programas gratuitos e acessíveis em todos sistemas operacionais. A professora do componente orientou todas as etapas da elaboração dos mecanismos, sobretudo apresentando aos estudantes, pela primeira vez, programas para desenhar modelos de moléculas e recursos para escrever reações orgânicas, além de ensinar a fazer animações. Foram apresentados aos estudantes programas para representação de compostos orgânicos, tais como: ChemDraw ${ }^{\circledR}$ ou Symyx Draw ${ }^{\circledR}$. Conheceram os comandos básicos para utilização do portal ChemTube $3 D^{\circledR}$ e $J_{m o l}{ }^{\circledR}$, bem como os recursos do $A C D / L a b s^{\oplus}$ para representação das reações.

Os estudantes também foram orientados a elaborar legendas, suscintas e objetivas, que representassem resumidamente as etapas dos mecanismos. Para garantir que a sequência de imagens se configurasse como uma animação, salientou-se a impontância do alinhamento dos quadros, de modo que fosse mantido um ponto fixo para o olhar do observador, mantendo todas as estruturas em mesma escala, para garantir a continuidade das imagens e a passagem entre as imagens deve ser suavizada. Dessa maneira, uma sequência de imagens, se converte em uma boa animação.

A Tabela 1 apresenta os diversos programas utilizados para desenhar as moléculas, usar as setas de reações e as setas de movimentação dos elétrons e elaborar as animações. Há softwares equivalentes para os mesmos fins em diferentes sistemas operacionais; os que são comercializados estão licenciados para uso na Instituição; outros utilizados neste trabalho são de acesso livre.

Devido ao número reduzido de vídeos com mecanismos de reações orgânicas que tenham sido elaborados e escritos no Brasil, optou-se por manter as legendas em português, o idioma de origem. Dessa maneira, para escrevê-las e preparar as imagens dos mecanismos, foi importante fazer um criterioso levantamento bibliográfico sobre a teoria envolvida do mecanismo a ser apresentado, por meio da consulta aos livros didáticos de Química Orgânica, utilizando duas ou três obras diferentes. ${ }^{25,26}$ Essa estratégia foi utilizada para auxiliar o estudante a ler e reler o assunto, a fim de criar um texto curto e explicativo, que coincidisse com tempo da imagem, garantindo a sincronia entre a animação e a descrição das etapas dos mecanismos. A etapa de elaboração da atividade foi de duas a três semanas.

Durante as aulas teóricas, discutiam-se e estudavam-se os fundamentos teóricos dos mecanismos trabalhados, ilustrados por alguns exemplos de animações, sejam elas elaboradas por nós em turmas de semestres anteriores, ou exemplos apresentados em portais educacionais internacionais, de livre acesso, como o ChemTube 3D.

Os estudantes foram orientados a criar em média dez imagens por quadro, cuidadosamente alinhadas para garantir a continuidade da animação. As imagens foram salvas, no formato jpg ou jpeg, com números sequenciais e exportadas para o programa de animação e passavam a ser chamadas de quadros. As transições e a duração de cada quadro foram escolhidas a fim de enfatizar as etapas mais importantes do mecanismo, tais como: a formação de intermediários; o estado de transição; o produto final; os fenômenos de estereoquímica, aspectos que tornavam a animação mais dinâmica e didática. Quando todas as imagens já estavam devidamente arrumadas e legendadas, o projeto, então, era salvo em formato de vídeo. Os vídeos concluídos foram socializados entre os colegas da turma e disponibilizados on-line para um grupo fechado. Ao final do semestre os alunos responderam à seguinte pergunta: Fale sobre o processo de elaboração das animações para a aprendizagem de Mecanismos de Reações Orgânicas.

\section{RESULTADOS E DISCUSSÃO}

$\mathrm{Na}$ elaboração de animações por meio do processo quadro a quadro, todas as imagens devem ser desenhadas uma a uma, representando a movimentação das moléculas, migração de elétrons, formação e rearranjo de intermediários, abandono dos grupos de saída e formação dos produtos. O principal desafio, para o desenvolvimento das animações, foi encontrar um programa adequado para elaborar as imagens das estruturas. Inicialmente, as imagens eram feitas em um programa específico para Química denominado Chem Window ${ }^{\circledR}$; porém, as estruturas feitas em programas equivalentes para desenho de moléculas orgânicas, tais como: Symyx Draw ${ }^{\circledR}$, Chem Window ${ }^{\circledR}$ ou ChemDraw ${ }^{\circledR}$, eram representadas em formato "linha", pois não possuíam um recurso que fizesse a conversão para o formato "bastão-bola" que representaria melhor o aspecto tridimensional das moléculas, bem como o volume dos átomos. Algumas tentativas foram feitas elaborando as estruturas no $A C D / L_{a b s}{ }^{\circledast}$ - ChemSketch. Apesar desse programa apresentar as imagens no formato "bastãobola", as ligações duplas e triplas, neste modelo, não apareciam evidenciadas. Optou-se, então, por elaborar as estruturas em um portal on-line denominado ChemTube $3 D^{\circledR}$, disponível na página da University of Liverpool.

As Figuras 1a-1c mostram as estruturas do cicloexeno nos três programas citados. Quando as imagens são feitas com o aplicativo Symyx Draw ${ }^{\circledR}$, os modelos estão no formato "em linha". Com o aplicativo $A C D / L a b s^{\circledast}$ - ChemSketch, as estruturas químicas não representam as ligações duplas e triplas, sendo, portanto, inadequados à elaboração dos mecanismos de eliminação e adição à dupla. Após algumas tentativas, as estruturas passaram a ser desenhadas usando o ChemTube $3 D^{\circledR}$ e Jmol $^{\circledR}$ que permitem desenhar bons modelos moleculares tridimensionais, os quais destacam as ligações insaturadas e o volume dos átomos.

A etapa de planejamento das animações é muito importante no processo, pois, nesse momento, os estudantes trabalham em duplas, podendo reelaborar os conceitos estudados, de modo a estimular o aprofundamento sobre os aspectos essenciais dos mecanismos, lendo

Tabela 1. Programas utilizados para elaboração das animações

\begin{tabular}{|c|c|c|c|}
\hline Programa (software) & Aplicação & Tipo & Endereço eletrônico \\
\hline Chemtube $3 D^{\circledR}$ & $\begin{array}{l}\text { Desenho de estruturas de moléculas } \\
\text { em 3D. }\end{array}$ & On-line acesso gratuito & www.chemtube3D.com \\
\hline$A C D / L_{a b s}{ }^{\boxplus}$ - ChemSketch & $\begin{array}{c}\text { Desenho de reações, setas de reações e } \\
\text { setas curvas. }\end{array}$ & Versão de demonstração & www.acdlabs.com \\
\hline Symyx Draw ${ }^{\circledR}$ ou equivalente & $\begin{array}{l}\text { Desenho de reações orgânicas, estrutu- } \\
\text { ras } 2 \mathrm{D} \text {, setas de reações e setas curvas. }\end{array}$ & Programa gratuito & https://symyx-draw.en.softonic.com \\
\hline Paint $^{\circledR}$ ou equivalente & Editoração de imagens. & Pacote Windows ${ }^{\circledR}$ & Windows $^{\circledR}$ \\
\hline Movie Maker ${ }^{\boxplus}$ ou equivalente & $\begin{array}{c}\text { Planejamento das animações usando } \\
\text { uma sequência de imagens. }\end{array}$ & Pacote Windows ${ }^{\circledR}$ & Windows $^{\circledR}$ \\
\hline Power Point ${ }^{\circledR}$ ou equivalente & $\begin{array}{c}\text { Planejamento das animações usando } \\
\text { uma sequência de imagens. }\end{array}$ & Pacote Windows ${ }^{\circledR}$ & Windows $^{\circledR}$ \\
\hline
\end{tabular}




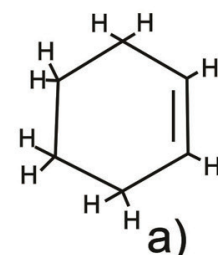

a)

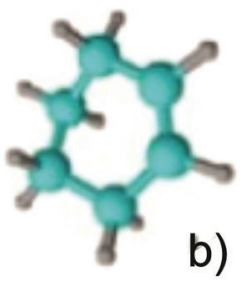

b)

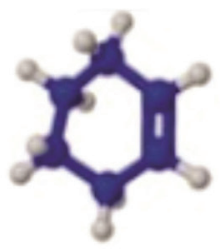

c)

Figura 1. Modelos do ciclo-hexeno: a) Symyx Draw ${ }^{\circledR}$; b) ChemSketch $^{\circledR}$; c) ChemTube $3 D^{\circledR}$

e relendo o assunto para escrever um texto próprio que contenha uma explicação do mecanismo. Compreende-se, dessa forma, que essa etapa é fundamental para entender dos aspectos teóricos relacionados ao conteúdo, pois desperta a imaginação e aguça a visualização tridimensional.

A cada semestre, os estudantes elaboram diferentes animações relacionadas ao assunto da unidade. Os mecanismos de substituição nucleofílica alifática $S_{\mathrm{N}} 1$ e $S_{\mathrm{N}} 2$, e mecanismos de eliminação E1 e E2, foram escolhidos por permitirem a discussão de aspectos importantes, como estereoquímica das reações, impedimento estérico, hibridização, reatividade dos substratos, dos nucleófilos ou eletrófilos, estrutura, estabilidade e rearranjos dos intermediários, como também aspectos cinéticos e termodinâmicos.

$\mathrm{Na}$ elaboração dos vídeos, os estudantes foram orientados a dar ênfase à estereoquímica da reação, à formação e à estrutura dos intermediários e aos estados de transição. As cenas que envolvem os aspectos mais importantes dos mecanismos ganham um tempo maior no planejamento das animações. Durante a elaboração das animações, é fundamental representar a inversão da configuração, para o mecanismo da reação de substituição nucleofílica bimolecular $\left(\mathrm{S}_{\mathrm{N}} 2\right)$; destacar a formação e a estrutura trigonal planar do carbocátion, intermediário nos mecanismos unimoleculares $\mathrm{S}_{\mathrm{N}} 1$ e E1; representar o arranjo antiperiplanar para o mecanismo da reação de Eliminação Bimolecular (E2); e destacar a estereoquímica dos produtos formados. Esses detalhes levam os estudantes a discutir mais profundamente aspectos específicos e mais complexos dos mecanismos estudados; desperta para uma maior observação aos pormenores que só podem ser mostrados com o mecanismo em animação, auxiliando-lhes, assim, o desenvolvimento cognitivo e a aprendizagem sobre os mecanismos envolvidos. Durante a etapa de elaboração, percebeu-se que uma dupla deixou de representar a configuração antiperiplanar inerente à reação de Eliminação Bimolecular, e esse equívoco foi contornado para a versão final da animação.

O ChemTube $3 D^{\circledR}$ utiliza o programa $\mathrm{Jmol}^{\circledR}$, um programa de acesso livre com estruturas interativas, ou seja, que podem ser movidas e/ou giradas pelo estudante com auxilio de um mouse, podendo ser atualizado e melhorado por programadores.

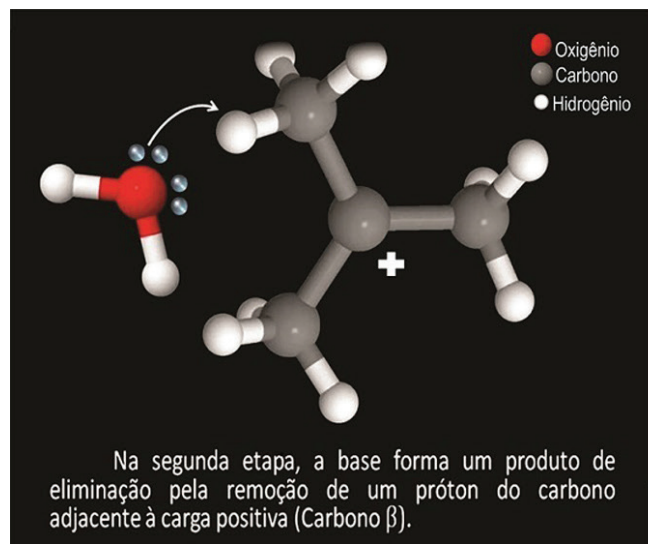

Um Mecanismo de Eliminação Unimolecular (E1) de 2-metil-2-bromopropano está demonstrado na Figura 2, cuja imagem representa a segunda etapa do mecanismo em que o carbocátion, formado em meio ácido, sofre subsequente eliminação do próton e formação do alceno. Este processo costuma ser comparado à reação de Substituição Nucleofílica Unimolecular $\left(\mathrm{S}_{\mathrm{N}} 1\right)$ por serem mecanismos concorrentes. Outros estudantes elaboraram o mecanismo de formação do álcool terciário por reação de substituição nucleofílica do haleto terciário em meio ácido possibilitando assim, a comparação entre os dois mecanismos.

A Figura 3 apresenta a cena final do Mecanismo de Substituição Nucleofílica Bimolecular $\left(S_{N} 2\right)$, em que se destaca a inversão de configuração. Nesse caso, o perfil da reação foi sendo representado, simultaneamente ao desenvolvimento do mecanismo concertado, cuja inversão de configuração constitui-se em um aspecto inerente ao mesmo, evidenciada durante a animação e na cena final. $\mathrm{O}$ outro mecanismo concorrente, de Eliminação Bimolecular, tem como aspecto relevante a configuração antiperiplanar no estado de transição, e foi elaborado por outra dupla de estudantes.

Todas as cenas foram legendadas em português, de maneira que o leitor pudesse pausar do vídeo e traduzir o texto das legendas, o que seria mais indicado a estudantes de países não lusófonos; além disso, permitiria a leitura cuidadosa àqueles que possuem deficiência auditiva ou cognitiva. Tais critérios foram planejados para que os vídeos fossem um recurso didático inclusivo, valorizando o aprofundamento do estudo e a leitura das legendas.

Ao final da unidade os vídeos foram utilizados em uma atividade de socialização, oportunizando um estudo comparativo entre os mecanismos, de modo a facilitar o debate acerca dos conceitos que os permeiam. Os integrantes das duplas apresentaram seus projetos para o restante da turma e foram questionados sobre os conceitos envolvidos nas reações. Por se tratar de mecanismos vistos por todos os estudantes, essa etapa contribuiu para a consolidação do conhecimento construído ao longo de toda a unidade. No presente trabalho, foi possível comparar os mecanismos $\mathrm{S}_{\mathrm{N}} 1$ e $\mathrm{S}_{\mathrm{N}} 2$, E1 e E2, além de discutir a competitividade e estereoquímica observada nessas reações.

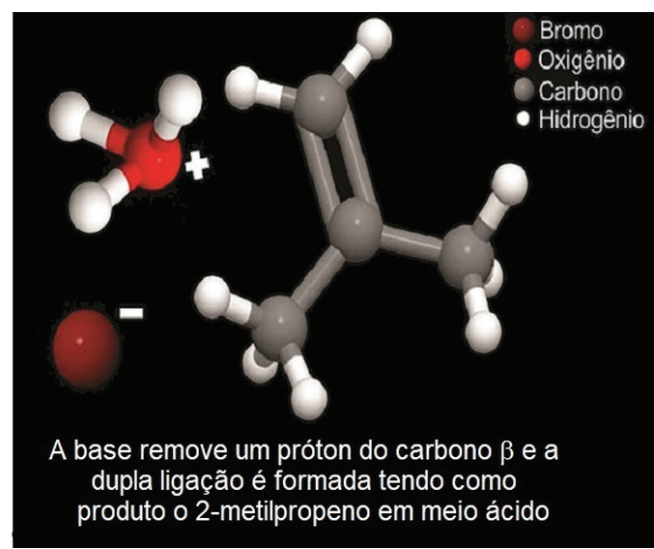

Figura 2. Imagens de dois momentos da animação do mecanismo de eliminação E1 


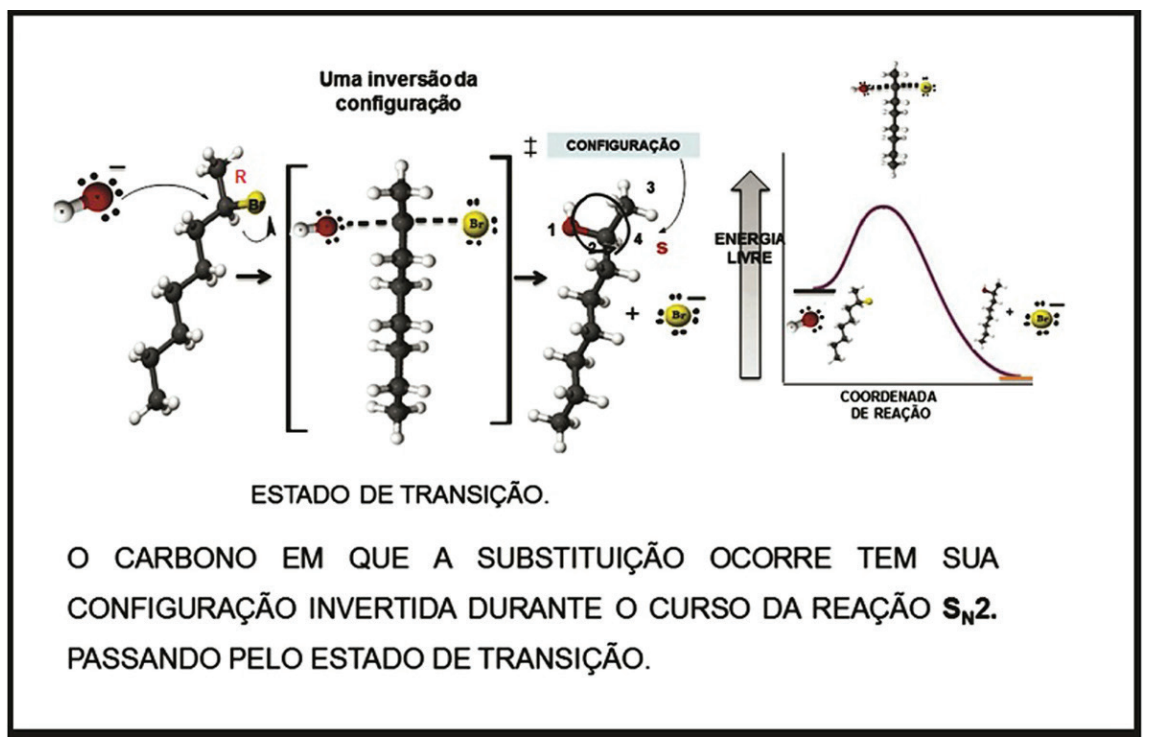

Figura 3. Mecanismo $S_{N} 2$

Com base na análise dos depoimentos apresentados na Tabela 2 , essa estratégia permite que o estudante compreenda as etapas do mecanismo de reação, levando-o ao aprofundamento do conteúdo por meio da pesquisa, além de ser uma atividade proveitosa, produtiva, criativa e fixadora. Pode-se verificar ainda que tal método contribui para o aprimoramento de saberes e para o domínio de recursos tecnológicos para produção de imagens e vídeos. Os relatos relativos à atividade não apenas destacaram a potencialidade do desenvolvimento de animações para a aprendizagem sobre mecanismos de reações orgânicas, como também para a utilização do objeto educacional como facilitador da aprendizagem. Pode-se inferir que essa estratégia didática acabou por auxiliar a aprendizagem acerca do tema estudado, estimulando o estudo detalhado dos mecanismos e a pesquisa para a elaboração de animações sobre mecanismos de outras reações orgânicas.

As respostas analisadas representam o reflexo do desenvolvimento de animações para a aprendizagem sobre mecanismos de reações orgânicas, como também para a utilização do objeto educacional como facilitador da aprendizagem. Esses foram os aspectos que nos motivaram a continuar com a atividade, visando ao desenvolvimento de novas animações para outros mecanismos.

Enfim, a atitude ativa de planejar, elaborar, desenhar, ler, reler explicações para escrever uma legenda curta, correta e esclarecedora, todas essas etapas levaram os estudantes a ter um contato mais

Tabela 2. Depoimentos dos alunos

\begin{tabular}{cl}
\hline Alunos & Depoimentos \\
\hline 1 & $\begin{array}{l}\text { "O processo de confecção dos mecanismos animados permite a } \\
\text { compreensão das etapas do mecanismo bem como dos interme- } \\
\text { diários das reaçães" }\end{array}$ \\
\hline 2 & $\begin{array}{l}\text { "O processo de criação do mecanismo foi produtivo porque preci- } \\
\text { samos conhecer a fundo o mecanismo para produzir a animação." }\end{array}$ \\
\hline 3 & $\begin{array}{l}\text { "Em minha opinião este trabalho é relevante no que diz respeito } \\
\text { ao aprofundamento do conteúdo e nos leva a se apropriar de } \\
\text { tecnologias que podem ser úteis no exercício da futura profissão." }\end{array}$ \\
\hline 4 & $\begin{array}{l}\text { "O processo de elaboração do mecanismo foi produtivo, uma vez } \\
\text { que precisamos pesquisar e aprofundar um pouco mais no assunto } \\
\text { para poder montar o mecanismo e as legendas." }\end{array}$ \\
\hline 5 & $\begin{array}{l}\text { "Desenvolver o mecanismo via animação foi criativo, proveitoso } \\
\text { e fixador. É preciso que o conteúdo esteja bem compreendido } \\
\text { para propor as animações." }\end{array}$ \\
\hline
\end{tabular}

profundo e frequente com o assunto, consequentemente ler e estudar mais. O envolvimento pessoal, o trabalho em dupla e todos os recursos cognitivos usados para executar tal atividade favoreceram a aprendizagem significativa.

\section{CONSIDERAÇÕES FINAIS}

A animação foi utilizada para criar e representar movimentos que, apesar de teoricamente previstos, não podem ser vistos na realidade e pela capacidade humana. A estratégia utilizada considerou o nível representacional (simbólico) para modelar as estruturas moleculares, as quais podiam ser manipuladas por meio do mouse de um computador. Por isso, esta é uma boa forma para apresentar e estudar mecanismos de reações orgânicas, posto que auxiliam o entendimento e a apreensão do que ocorre nas reações orgânicas em nível subatômico (submicroscópico).

Verificou-se, portanto, que essa atividade despertou o interesse dos estudantes para elaborarem suas próprias animações, o que levou-os a ler e reler os conteúdos e as explicações encontradas nos livros, além de desafiá-los ao uso de recursos disponíveis, de fácil utilização e manipulação. Foram exploradas novas tecnologias de forma alternativa, demonstrando a aplicação das tecnologias acessíveis e de programas simples, para elaboração de um objeto educacional próprio, único e inovador. Essa atividade levou os estudantes a interagirem diretamente com o objeto em estudo, que desencadeou o aprofundamento do conteúdo por meio da pesquisa sobre mecanismos de reações orgânicas e, por conseguinte, uma aprendizagem significativa.

O trabalho em dupla favoreceu a interação entre estudantes durante todas as etapas do desenvolvimento das animações, uma vez que discussões foram intensificadas, na busca do aprofundamento e aprendizagem efetiva sobre determinados aspectos e conceitos envolvidos nos mecanismos estudados.

Foram desenvolvidas animações de mecanismos das reações por meio de estruturas em 3D, elaboradas com programas gratuitos e acessíveis a todos os sistemas operacionais, podendo ser manipuladas até mesmo por quem não domina as linguagens de programação ou complexos aplicativos para modelagem teórica e editoração de imagens.

Como temos poucos exemplos com animações sobre mecanismos, optou-se por utilizar legendas explicativas sobre as etapas dos mecanismos. Essa estratégia auxiliou o estudante na compreensão do mecanismo estudado, a fim de elaborar frases curtas e explicativas que acompanhassem o ritmo da animação. A opção por legendas ampliou 
a abrangência e a acessibilidade aos vídeos. Dessa forma, esse recurso pode ser adotado no ensino de Química tanto para estrangeiros que não dominam o português quanto para deficientes auditivos.

Por ter legendas curtas, objetivas e explicativas o vídeo produzido pode ser utilizado por professores e estudantes de cursos técnicos, além de auxiliar o professor de Química quando for trabalhar o conteúdo de reações orgânicas.

Como pôde ser observado, este trabalho oportunizou ao estudante conhecer diferentes programas para desenho de estruturas de compostos orgânicos, participar da construção de dispositivos interativos para fazer animação e na visualização de estruturas em 3D.

O docente teve um papel estratégico de mediador nessa atividade, por apresentar aos alunos o desafio de elaborar suas próprias animações, apresentando-lhe recursos tecnológicos, programas e mecanismos para a sua realização. Dessa maneira, tornou-se possível verificar que a aprendizagem de mecanismos inicia na sala de aula e é complementada extraclasse durante a realização da atividade que consistiu em planejamento, elaboração e uso da animação.

As TICs visam modificar a relação dos estudantes com o assunto, buscando atraí-los ao aprendizado pela aproximação com as linguagens e descrições específicas, trazendo novas perspectivas na relação do processo de ensino e aprendizagem. Com a evolução dos programas para elaboração de modelos e para execução da animação, os resultados das animações passaram a ter uma boa resolução e boa apresentação. Essa evolução representa bem a importância e a viabilidade da utilização de modelos virtuais para o ensino de mecanismos de reações orgânicas. Consequentemente, essa atividade possibilitou a elaboração de um trabalho de qualidade, o qual poderá ser utilizado e reutilizado por estudantes que tenham acesso à internet, configurando assim um novo objeto educacional.

Os depoimentos oferecidos pelos alunos tanto representaram o quão significante foi o desenvolvimento de animações para a aprendizagem sobre mecanismos de reações orgânicas, como também para a utilização da ferramenta tecnológica como facilitadora da aprendizagem. Os resultados foram muito positivos e nos motivaram a continuar com a atividade, elaborando novos mecanismos e buscando dar ênfase ao aspecto tridimensional das moléculas.

Por fim, conclui-se que a proposta ora apresentada demonstrou aos Licenciandos em Química uma possibilidade nova, moderna, dinâmica e motivadora para se utilizar a tecnologia no ensino de Química Orgânica, elaborando Animações de Mecanismos de Reações Orgânicas. Esses vídeos estão disponíveis no Material Suplementar.

\section{MATERIAL SUPLEMENTAR}

Dois exemplos de vídeos com animações elaboradas neste trabalho estão disponíveis para download em http://quimicanova.sbq. org.br, em formato $w m v$, com acesso livre.

\section{AGRADECIMENTOS}

Agradecemos aos alunos das turmas de Química Orgânica II do curso de Licenciatura em Química da Universidade do Estado da Bahia que participaram do trabalho na elaboração das animações, identificação dos erros, reforçando os acertos e dando sugestões. Ficamos gratas à professora Eloina Valverde da Silva pela revisão ortográfica.

\section{REFERÊNCIAS}

1. MacCoss, M.; Baillie, T. A.; Science 2004, 303, 1810.

2. Paulson, D. R.; J. Chem. Educ. 1999, 76, 6.
3. Libby, R. D.; J. Chem. Educ. 1995, 72, 626.

4. Nelson, D. J.; Proc. Okla. Acad. Sci. 2000, 78, 71.

5. Johnstone, A. H.; Chem. Educ. Res. Pract. 2000, 1, 9.

6. Grove, N. P.; Lowery Bretz, S.; Chem. Educ. Res. Pract. 2012, 13, 201.

7. Yanfeng, D.; China Pap. 2004, 6.

8. Ausubel, D. P.; Aquisição e Retenção de Conhecimentos: Uma Perspectiva Cognitiva, $1^{\mathrm{a}}$ ed., Paralelo Editora: Porto, 2003.

9. Lafarge, D. L.; Morge, L. M.; Meeut, M. M.; J. Chem. Educ. 2014, 91, 173.

10. Galloway, K. R.; Stoyanovich, C.; Flynn, A. B.; Chem. Educ. Res. Pract. 2017, 18, 353 .

11. Weinrich, M. L.; Sevian, H.; Chem. Educ. Res. Pract. 2017, 18, 169.

12. Bradley, J. D.; Afr. J. Chem. Educ. 2014, 4, 64.

13. Rezende, F.; Revista Brasileira de Pesquisa em Educação em Ciências 2000, 2,70 .

14. Freire, P.; Pedagogia da Autonomia, $25^{\mathrm{a}}$ ed.; Paz e Terra: Rio de Janeiro, 2002.

15. Backes, N. F.; Prochnow, T. R.; Anais do $37^{\circ}$ Encontro Debates sobre o Ensino Química 2017, 1.

16. Taber, K. S.; Chem. Educ. Res. Pract. 2018, 19, 405.

17. Steffen, L. K.; Gill, M.; Gundersen, J.; Nelson, J. E.; Chem. Educ. 1996, 1,1 .

18. Moran, M.; Masetto, M. T.; Behrens, A.; Novas Tecnologias e Mediação Pedagógica, 10ª ed., Papirus: São Paulo, 2000.

19. Moran, J. M.; $12^{\circ}$ Endipe - Encontro Nacional de Didática e Prática de Ensino 2004, 245.

20. Freeman, S.; Eddy, S. L.; McDonough, M.; Smith, M. K.; Okoroafor, N.; Jordt, H.; Wenderoth, M. P.; Proc. Natl. Acad. Sci. 2014, 111, 8410.

21. Seery, M. K.; Chem. Educ. Res. Pract. 2015, 16, 758.

22. Tarouco, L. M. R.; da Costa, V. M.; Ávila, B. G.; Bez, M. R.; dos Santos, E. F.; Objetos de Aprendizagem: teoria e prática, Evangraf: Porto Alegre, 2014.

23. Cachapuz, A.; Praia, J.; Manuela, J.; Ciênc. Educ. 2004, 10, 363.

24. da Ponte, J. P.; Rev. Iberoam. Educ. 2000, 24, 63.

25. Clayden, J.; Greeves, N.; Warren, S.; Organic Chemistry, $1^{\text {st }}$ ed., Oxford University Press: Oxford, 2012.

26. Bruice, P. Y.; Química Orgânica, Pearson Pretince Hall: São Paulo, 2006.

27. Selwyn, N.; Educ. Soc. 2008, 29, 815.

28. Cysneiros, P.; Informática Educativa 1999, 12, 11.

29. Leite, B. S.; Sci. Nat. 2019, 1, 326.

30. Silva, G. S.; Braibante, M. E. F.; Pazinato, M. S.; Revista Brasileira de Pesquisa em Educação em Ciências 2013, 13, 159.

31. Al-Balushi, S. M.; Al-Hajri, S. H.; Chem. Educ. Res. Pract. 2014, 15, 47.

32. Sorden, S. D.; Informing Sci. J. 2005, 8, 263.

33. Mayer, R. E.; Moreno, R.; Educ. Psychol. Rev. 2002, 14, 87.

34. Mayer, R. E.; Learn. Instr. 2003, 13, 125.

35. Mayer, R. E.; Moreno, R.; Educ. Psychol. 2003, 38, 43.

36. Raiyn, J.; Rayan, A.; World J. Chem. Educ. 2015, $3,1$.

37. Johnstone, A. H.; Chem. Educ. Res. Pract. 2006, 7, 49.

38. Ferreira, C. R.; Arroio, A.; Quim. Nova Esc. 2013, 35, 199.

39. Almeida, T. A.; de Castro, C. F.; Cavalcanti, E. L. D.; Revista Tecnologias na Educação 2014, 6, 17.

40. Brown, W. H.; Introdution to Organic Chemistry, $2^{\text {nd }}$ ed., Oxford University Press: Oxford, 2000.

41. Lipshutz, B. H.; Mechanisms in Motion: Windows Student Version 1.5 2010, 4-6.

42. Royal Society Chemistry Mechanism Inspector, disponível em http:// www.rsc.org/learn-chemistry/resources/mechanism-inspector/, acessado em Julho 2020.

43. Roger Frost's Organic Chemistry, disponível em https://organic. rogerfrost.com/links/, acessado em Julho 2020. 
44. Greeves, N.; ChemTube3D ${ }^{\circledR}$, disponível em http://www.chemtube3d. com/, acessado em Julho 2020.

45. Baptista, M. M.; Desenvolvimento e Utilização de Animações em $3 D$ no Ensino de Química, UNICAMP: Campinas, 2013.

46. Figueiredo, L. V.; da Silva, E. K. S.; de Oliveira, F. M. F.; Gomes, L. A. P.; III Congresso Nacional de Educação, Diamantina, 2017.

47. Silveira, F. A.; Vasconcelos, A. K. P.; Revista Tecnologias da Educação 2017, 23, 1 .

48. Cavalcante, A. I. C.; Ferreira, M. K. A.; de Macêdo, L. N.; VII Congresso Norte Nordeste de Pesquisa e Inovação, Palmas, 2012.
49. Silva, F. N. da; Souza, A. A. de; Santos, B. L. dos; Ferreira, M. dos S.; Anais do I Congresso de Inovação Pedagógica em Arapiraca, Arapiraca, 2015.

50. Vlacholia, M.; Vosniadou, S.; Roussos, P.; Salta, K.; Kazi, S.; Sigalas, M.; Tzougraki, C.; Chem. Educ. Res. Pract. 2017, 18, 763.

51. Hehre, W. J.; Shusterman, A. J.; Molecular Modeling in Undergraduate Chemistry Education, 2000, 18.

52. Babaev, E. V.; Chem. Heterocycl. Compd. 1995, 31, 997.

53. Conceição, L. S. M. da; Mendonça, M. V.; Simon, J. P.; Revista de Graduação USP 2017, 2, 135. 